\title{
Assessment of Heavy Metals and Radionuclide Concentrations in Mafikeng Waste Water Treatment Plant
}

\author{
Manny Mathuthu, Roseline Olobatoke* \\ Centre for Applied Radiation Science and Technology, North-West University, Mafikeng Campus, Mmabatho, \\ South Africa \\ Email: "yemisirose205@yahoo.com
}

Received 18 June 2015; accepted 22 January 2016; published 25 January 2016

Copyright @ 2016 by authors and Scientific Research Publishing Inc.

This work is licensed under the Creative Commons Attribution International License (CC BY). http://creativecommons.org/licenses/by/4.0/

c) (i) Open Access

\begin{abstract}
A study was carried out to assess the heavy metal and radionuclide concentrations of water from the waste water treatment plant in Mafikeng Local Municipality. Ten water samples were collected from various stages of water treatment $(n=2$ per stage) which included sewage delivered to the plant, the two treatment stages, the effluent and the community water. Samples were analyzed for heavy metal content using Inductive Coupled Plasma Mass Spectrometer. Gross $\alpha / \beta$ activity concentrations in water samples were evaluated by Liquid Scintillation Counting whereas the concentration of individual radionuclides was measured by gamma spectroscopy. The results showed marked reduction in the levels of heavy metal concentration from $3 \mu \mathrm{g} / \mathrm{L}$ (As) $-670 \mu \mathrm{g} / \mathrm{L}(\mathrm{Na})$ in sewage into the plant to $2 \mu \mathrm{g} / \mathrm{L}$ (As) $-170 \mu \mathrm{g} / \mathrm{L}$ (Fe) in the effluent. The gross $\alpha$ activity in all the water samples (7.7 - 8.02 Bq/L) exceeded the $0.1 \mathrm{~Bq} / \mathrm{L}$ limit set by World Health Organization (WHO). Gamma spectroscopy revealed very high concentrations of ${ }^{235} \mathrm{U}$ and ${ }^{226} \mathrm{Ra}$ in water samples, with the lowest concentrations $(9.35$ and $5.44 \mathrm{~Bq} / \mathrm{L}$, respectively) in the in-coming sewage and highest concentrations (73.8 and $47 \mathrm{~Bq} / \mathrm{L}$, respectively) in the community water. All the values were considerably higher than the limits of South Africa Target Water Quality Range and WHO. However, the estimated total doses of the two radionuclides for the analyzed water samples (10.62 - $45.40 \mu \mathrm{Sv} \cdot \mathrm{yr}^{-1}$ ) were all well below the reference level of the committed effective dose of $100 \mu \mathrm{Sv} \cdot \mathrm{yr}^{-1}$ recommended by WHO.
\end{abstract}

\section{Keywords}

Heavy Metals, Radionuclides, ${ }^{235} \mathrm{U},{ }^{226} \mathrm{Ra}$, Water

\footnotetext{
${ }^{*}$ Corresponding author.
}

How to cite this paper: Mathuthu, M. and Olobatoke, R. (2016) Assessment of Heavy Metals and Radionuclide Concentrations in Mafikeng Waste Water Treatment Plant. Journal of Water Resource and Protection, 8, 93-99. 


\section{Introduction}

Water is a natural resource that forms an integral part of any ecosystem. Access to clean water is a key resource for reducing poverty and disease, and improving the life of any human population [1]. South Africa is a country plagued with unpredictable rainfall (which averages $500 \mathrm{~mm} / \mathrm{a}$ ), high evaporation rates and low conversion of rainfall to runoff. These shortcomings make South Africa a water-stressed nation, where demand is almost closing in on supply. The North West Province, where Mafikeng is located, is an arid province that experiences all of the aforementioned water resource constraints. The Mafikeng community water supply is sourced mainly from surface water (Setumo dam) and groundwater (Molopo and Grootfontein well-fields), both of which are rapidly depleting due to insufficient rainfall, agricultural/industrial and mining activities [2]. The water resource constraints are further compounded by quality deterioration due to pollution accruing from domestic sewage, industrial effluents, acid mine drainage and agricultural runoff chemicals (fertilizers, pesticides and herbicides). Naturally, groundwater contains varying concentrations of radioactive metals such as uranium, thorium and their daughter products [3]. Also, each aforementioned pollution point-source has the potential to raise the levels of concentration of heavy metals and radionuclide contents of surface water. Both water resource bodies, if not properly treated to remove radionuclides and heavy metals, may contribute significantly to internal radiation dose through drinking water. In addition, the current Mafikeng water consumption exceeds the calculated required needs, necessitating a cycle of water re-use [4] (Figure 1). This makes water treatment an issue of paramount importance in the locality, if public health must be protected. A few functioning wastewater (WWTW) and water treatment (WTW) infrastructures are located within the municipality (Figure 2). However, the quality

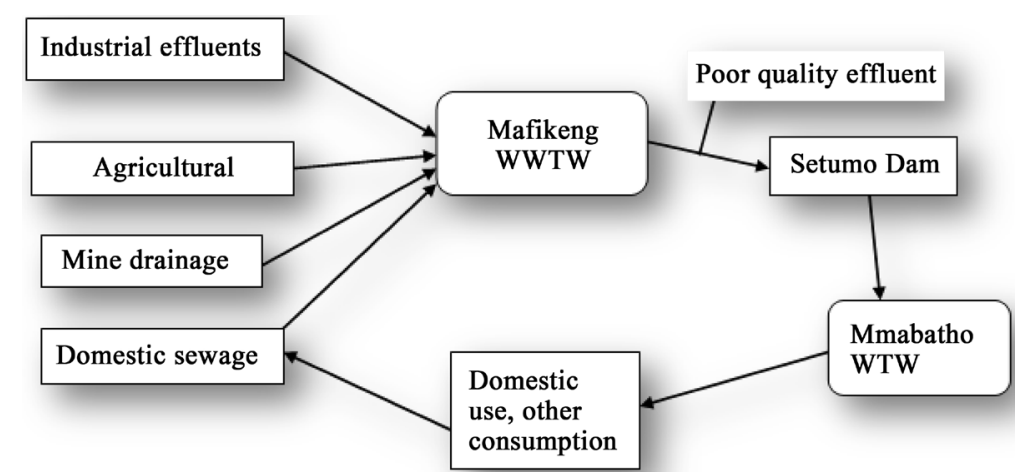

Figure 1. Mafikeng local municipality water recycle system (adapted from [4]).

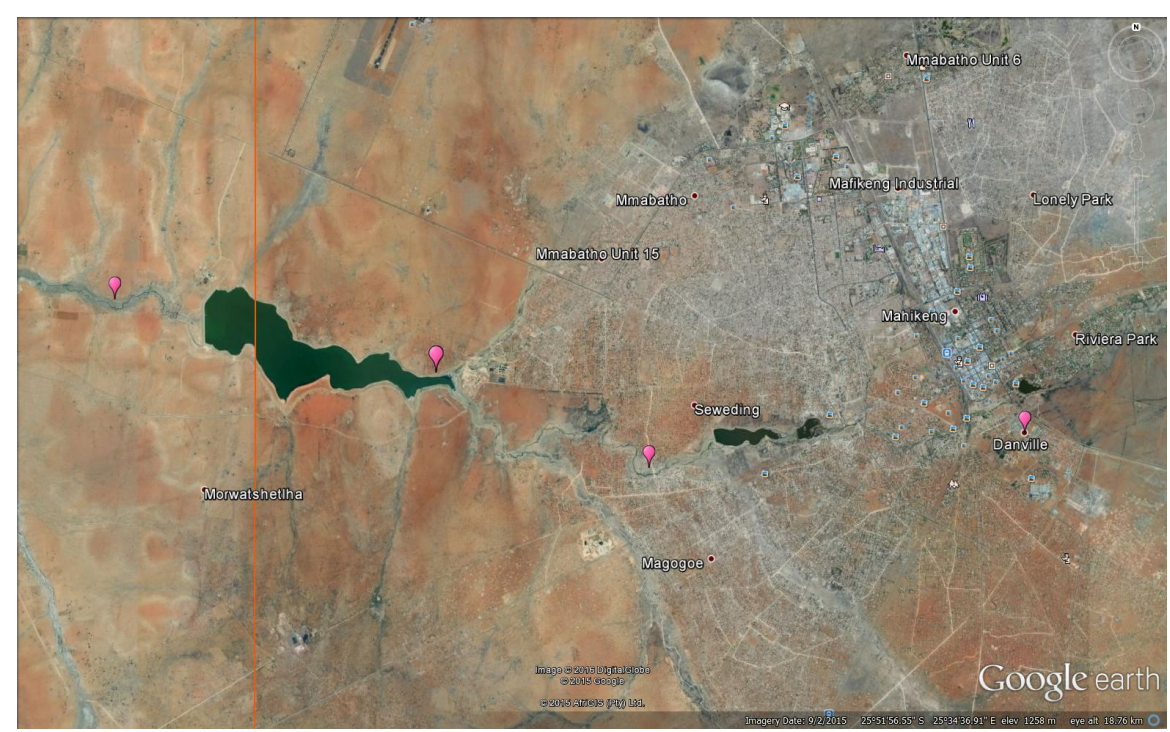

Figure 2. Map of Mafikeng local municipality showing locations (indicated by drop) for water treatment infrastructures. MWWTW = Mafikeng waste water treatment works. 
of the effluent which is discharged from the WWTW to the Setumo dam where water is abstracted for domestic use is poor. There are no available data on the radionuclide concentration of wastewater delivered to the WWTW or the water released from the treatment plant to the dam. The present study was therefore conducted to determine the levels of radionuclide and heavy metal concentration in the water from Mafikeng wastewater treatment plant and water subsequently delivered for domestic consumption.

\section{Materials and Methods}

\subsection{Sampling Area}

The North West Province is located on latitude $25.8^{\circ} \mathrm{S}$ and longitude $25.5^{\circ} \mathrm{E}$ and offers an almost year-round sunshine, with average rainfall of $300-500 \mathrm{~mm}$ annually. This study was carried out within the Mafikeng Local Municipality (MLM), the biggest municipality in the Province which covers an area of about $3703 \mathrm{~km}^{2}$ and consists of 102 villages and suburbs. Economic activities within the municipality consist of agriculture, agro-industries and tertiary sectors.

\subsection{Sample Evaluation of Heavy Metals}

The concentration of heavy metals in the water samples was determined using the Inductive Coupled Plasma Mass Spectrometer (Perkin Elmer NexION 300Q) located at the Animal Health Centre of the North West University, Mafikeng Campus. Prior to analysis, samples were digested as described by [5] with modifications. To 5 $\mathrm{ml}$ aliquot of samples, $5 \mathrm{ml}$ of $55 \% \mathrm{HNO}_{3}, 5 \mathrm{ml}$ of $32 \% \mathrm{HCl}$ and $1 \mathrm{ml}$ of $100 \mathrm{vol} . \mathrm{H}_{2} \mathrm{O}_{2}$ were added, followed by heating in a microwave for $45 \mathrm{~min}$. The mixture was allowed to cool for $20 \mathrm{~min}$ and later transferred to pre-rinsed $100 \mathrm{ml}$ volumetric flask where it was topped with distilled water to make $100 \mathrm{ml}$. The mixture was left at room temperature overnight and thereafter transferred to $15 \mathrm{ml}$ centrifuge tubes without disturbing the sediments.

\subsection{Determination of Radionuclides Concentration in Water}

Determination of gross alpha/beta activities in water samples was carried out by Liquid Scintillation Counting (LSC) using the Perkin Elmer Quantulus 1220 Ultra-Low Level LSC coupled to alpha-beta discrimination (Todorović et al., 2012). A $10 \mathrm{ml}$ aliquot of each filtered and acid-preserved water sample was added to $8 \mathrm{ml}$ of Ultima Gold ULLT Cocktail (Perkin Elmer, Boston, USA) in a $20 \mathrm{ml}$ vial. The water samples were then run on the Quantulus 1220 Ultra Low-Level LSC set at $4 \mathrm{~h}$ counting time, 3 cycles and 1 repetition per sample vial. The radionuclide concentrations in samples were determined using HPGe detector model GC2020 E7500 CSL (Canberra GMbH) \{resolution (FWHM) at $122 \mathrm{keV}\left({ }^{57} \mathrm{Co}\right)$ is $0.94 \mathrm{keV}$ and at $1332 \mathrm{keV}\left({ }^{60} \mathrm{Co}\right)$ is $1.77 \mathrm{keV}$ and relative efficiency for energy $1.33 \mathrm{MeV}$ relative to (NaI)TI is $20 \%$. The detector was coupled to a computer through an MCA (DSA 1000, Canberra). The detector was calibrated for energy and efficiency using the Canberra standard calibration file. Each sample was counted for $24 \mathrm{~h}$. The Genie 2000 software was used for both Data acquisition and analysis (nuclide identification).

\subsection{Estimation of the Annual Intake Dose}

The annual intake dose (AID) of some important radionuclides through drinking water over one year period for all age groups was calculated for community water using the following equation [6]

$$
A I D=I \times A \times C
$$

where $I$ is annual water consumption $(\mathrm{L} / \mathrm{a}), A$ is the activity concentration $(\mathrm{Bq} / \mathrm{L})$ and $C$ is the dose conversion factor for each radionuclide. The dose conversion factors and annual water consumption (L/a) for different age groups was extracted from DWAF (2002) guidelines [7]. The total annual dose was calculated as the arithmetic summation of annual intake dose of two radionuclides $\left({ }^{235} \mathrm{U}\right.$ and $\left.{ }^{226} \mathrm{Ra}\right)$.

\section{Results and Discussion}

\subsection{Concentration of Heavy Metals in Water Samples}

The heavy metal concentration of analyzed water samples is shown in Table 1 . The values of all the metals detected in samples obtained from the Mafikeng WWTW were within limits stipulated by the Department of Wa- 
ter Affairs (DWA) and World health Organization (WHO) although there were staggering variations in values at different processing stages. This could be due to effects of treatment. However, most of the metals were not detected in the water out samples (i.e. effluents released to the Setumo dam) except vanadium, iron and arsenic which were also far below stipulated limits. This observation is a suggestion that the water treatment carried out at the WWTW may be very efficient in removing the heavy metal contents of the wastewater delivered to it.

\subsection{Gross $\alpha / \beta$ Concentrations of Water Samples}

The gross $\alpha / \beta$ activities in water samples as determined by liquid scintillation counting are presented in Table 2 . The gross $\beta$ activity concentration of water delivered to the treatment plant was within limits of both South Africa Target Water Quality Range (SA-TWQR) and WHO. The activity was not detected at the two treatment stages and the effluent released from the treatment plant. In contrast, the gross $\alpha$ activity concentration of samples highly exceeded the limits set by WHO for water. The gross $\alpha$ concentration in water sample from first treatment stage was higher than that of the waste water delivered to the plant although there were little but steady decreases in the second treatment stage and the effluent. Perhaps the first stage of the water treatment involved the use of chemicals/substances that contain alpha-emitting particles which invariably must have increased the gross alpha concentration of the water. The treatment applied in the second stage however, seemed not to have been efficient in removing the alpha emitters hence the high concentration in the effluent. It has been noted that gross alpha activity, in particular, is a sensitive and immediate indicator of the concentrations of uranium isotopes ${ }^{234} \mathrm{U},{ }^{235} \mathrm{U}$ and ${ }^{238} \mathrm{U}$ ) and ${ }^{226} \mathrm{Ra}$ in water [10]. Because of the high radiotoxicity of these common $\alpha$-emitters, the gross $\alpha$ concentration recorded in the current study calls for concern and further evaluation of the individual radionuclide activity concentration for the purpose of risk assessment. This is in view of the fact that the effluent from the treatment plant drains into the Setumo dam where water for domestic use is abstracted.

\subsection{Radionuclide Concentrations of Water Samples as Determined by Gamma Spectroscopy}

The trend observed in the concentrations of both Uranium-235 and Radium-226 radionuclides from waste water entering the treatment plant $\left({ }^{235} \mathrm{U}=9.75 \mathrm{~Bq} / \mathrm{L}\right.$ and $\left.{ }^{226} \mathrm{Ra}=5.44 \mathrm{~Bq} / \mathrm{L}\right)$ to the effluent $\left({ }^{235} \mathrm{U}=16 \mathrm{~Bq} / \mathrm{L}\right.$ and ${ }^{226} \mathrm{Ra}$ $=5.56 \mathrm{~Bq} / \mathrm{L}$ ) in Table 3 may be an indication of poor efficiency of the employed water treatment method in removing the radionuclides. This could cause the respective radionuclides which naturally have long half-lives $\left({ }^{235} \mathrm{U}=700\right.$ million and ${ }^{226} \mathrm{Ra}=1600$ years $)$ to accumulate in the system over time leading to further contamination of water during processing. Furthermore, it was previously noted that effluents delivered into the Setumo dam (source of water for domestic use) are of poor quality, and which eventually reduces the efficiency of the final water treatment at Mmbatho water treatment plant [11]. This could be a contributing factor to the exceedingly high concentrations of the radionuclides in the community water $\left({ }^{235} \mathrm{U}=73.8 \mathrm{~Bq} / \mathrm{L}\right.$ and $\left.{ }^{226} \mathrm{Ra}=47 \mathrm{~Bq} / \mathrm{L}\right)$. This is in addition to probable contamination of the community water delivery system as a result of previous radionuclide accumulations, which in turn may contaminate the delivered water. It has been reported that most water treatment methods generate waste products containing concentrated radionuclides which if not properly handled or treated, become a source of radiation in itself [12]. However, the studies of [3] in South India showed that water treatment by reverse osmosis reduced the concentrations of natural radionuclides in drinking water. The high activity concentration of uranium and radium nuclides observed in this study agrees with reports of [13], who also noted high dose contributions of radium $(48.0 \% \pm 27.9 \%)$ and uranium $(20.3 \% \pm 14.1 \%)$ in drinking water in Italy. Evaluation of activity concentration of ${ }^{226} \mathrm{Ra}$ in drinking waters from oil fields and host communities in Nigeria revealed average concentration that was well above the WHO permissible levels [6]. Uranium and radium are natural radionuclides of practical importance in terms of drinking water due to their effects on health. Radium tends to accumulate in the bony skeleton leading to increased risk of bone cancer particularly when the activity concentration is above $0.42 \mathrm{~Bq} / \mathrm{L}$. Uranium has affinity for kidneys and liver making its chemical toxicity to be of greater concern than the radiological cancer risk. Short term risk of renal damage may occur with activity concentration of uranium greater than $18 \mathrm{~Bq} / \mathrm{L}$ of drinking water [8]. The estimated annual intake dose and the total annual radiation dose $\left(\mu \mathrm{Sv} \cdot \mathrm{yr}^{-1}\right)$ resulting from consumption of ${ }^{235} \mathrm{U}$ and ${ }^{226} \mathrm{Ra}$ in drinking water are presented in Table 4.

Despite the high activity concentrations of the two natural radionuclides in the community water, the estimated total doses for the analyzed water samples were all well below the reference level of the committed 


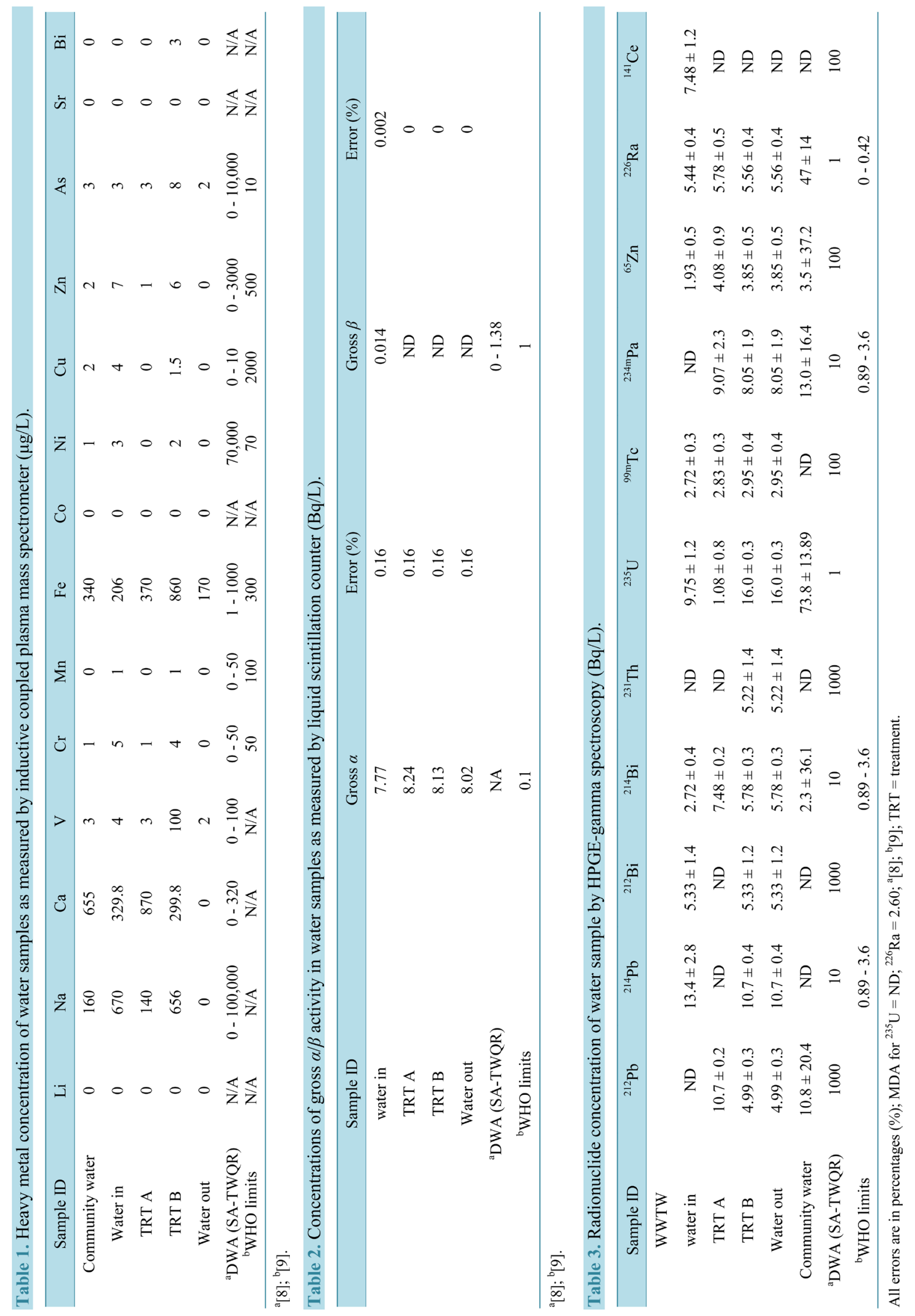


Table 4. Estimated intake dose $\left(\mu \mathrm{Sv} \cdot \mathrm{yr}^{-1}\right)$ and total annual dose of ${ }^{235} \mathrm{U}$ and ${ }^{226} \mathrm{Ra}$ from drinking water in different age groups.

\begin{tabular}{cccc}
\hline \multirow{2}{*}{ Age group (yrs) } & Annual intake dose of individual nuclides $\left(\mu{\left.\mathrm{Sv} \cdot \mathrm{yr}^{-1}\right)}\right.$ & Total annual dose from drinking water $\left(\mu \mathrm{Sv} \cdot \mathrm{yr}^{-1}\right)$ \\
\cline { 2 - 3 } $1-2$ & ${ }^{235} \mathrm{U}$ & 11.73 & 14.23 \\
$2-7$ & 2.49 & 8.74 & 10.62 \\
$7-12$ & 1.88 & 13.16 & 14.99 \\
$12-17$ & 1.83 & 42.30 & 45.40 \\
$>17$ & 3.10 & 9.61 & 12.14 \\
\hline
\end{tabular}

effective dose of $100 \mu \mathrm{Sv} \cdot \mathrm{yr}^{-1}$ recommended by WHO [14]. This is an indication that the community water analyzed may not pose a radiological risk to the consumers.

\section{Conclusion}

Results of the evaluation of heavy metal and radionuclide concentrations of water from the Mafikeng waste water treatment plant and the community water suggest that the water treatment method employed may be efficient in removing heavy metals from sewage delivered to the plant but not the radionuclides particularly ${ }^{235} \mathrm{U}$ and ${ }^{226} \mathrm{Ra}$. The increasing trend in the concentrations of these radionuclides from the delivered sewage to the effluent and finally to the end users may suggest contamination along water processing line and the final water delivery system. Despite this observation, the community water analyzed may not pose any radiotoxic risk to the community because the estimated total annual dose from analyzed water samples was far below reference level recommended by World Health Organization. However, improvements in the methods and facilities currently used for water treatment at the Mafikeng WWTW and proper care of the community water delivery system may go a long way in improving the quality of water delivered to the Mafikeng people.

\section{Acknowledgements}

The authors would like to thank the NRF and FAST FRC for providing the funds for this research, and also Ms. Mpho Tfheole for her assistance during the laboratory analysis of samples.

\section{References}

[1] Mukheibir, P. and Sparks, D. (2003) Report for Phase 1 of the Sustainable Development and Climate Change Project. EDRC, University of Cape Town.

[2] Merwe, V.-D. (2010) Comments from Paul van der Merwe, Water Sector Support Directorate, North-West Region, Department of Water Affairs.

[3] Manu, A., Santhanakrishnan, V., Rajaram, S. and Ravi, P.M. (2014) Concentration of Natural Radionuclides in Raw Water and Packaged Drinking Water and the Effect of Water Treatment. Journal of Environmental Radioactivity, 138, 456-459. http://dx.doi.org/10.1016/j.jenvrad.2014.08.013

[4] RSMC (2010) Development of a Reconciliation Strategy for All Towns in the Northern Region. Report, 1-19.

[5] Creed, J.T., Brockhoff, C.A. and Martin, T.D. (1994) Determination of Trace Elements in Waters and Wastes by Inductively Coupled Plasma-Mass Spectrometry. Published by Environmental Monitoring Systems Laboratory, Office of Research and Development, US Environmental Protection Agency, Cincinnati.

[6] Agbalagba, E.O., Avwiri, G.O. and Ononugbo, C.P. (2013) Activity Concentration and Radiological Impact Assessment of ${ }^{226} \mathrm{Ra},{ }^{228} \mathrm{Ra}$ and $40 \mathrm{~K}$ in Drinking Waters from (OML) 30, 58 and 61 Oil Fields and Host Communities in Niger Delta Region of Nigeria. Journal of Environmental Radioactivity, 116, 197-200. http://dx.doi.org/10.1016/j.jenvrad.2012.08.017

[7] DWAF (Department of Water Affairs and Forestry) (2002) Radioactivity Dose Calculation and Water Quality Evaluation Guideline for Domestic Water Use. 43-44.

[8] DWAF (Department of Water Affairs and Forestry) (1996) Domestic Use. Department of Water Affairs and Forestry, Pretoria.

[9] WHO (World Health Organization) (2004) Guidelines for Drinking Water Quality. 3rd Edition, Vol. 1.WHO, Geneva. 
[10] Forte, M., Rusconi, R., Cazzaniga, M.T. and Sgorbati, G. (2007) The Measurement of Radioactivity in Italian Drinking Waters. Microchemical Journal, 85, 98-102. http://dx.doi.org/10.1016/j.microc.2006.03.004

[11] WSDP (2008) Central District Municipality: Water Services Development Plan Municipality Report.

[12] Hodgson, K. (2011) South African National Standards 241-1; Drinking Water Part 1: Microbiological, Physical, Aesthetic and Chemical Determinands. SABS Standard Division, RSA, 241.

[13] Jia, G. and Torri, G. (2007) Estimation of Radiation Doses to Members of the Public in Italy from Intakes of Some Important Naturally Occurring Radionuclides $\left({ }^{238} \mathrm{U},{ }^{234} \mathrm{U},{ }^{235} \mathrm{U},{ }^{226} \mathrm{Ra},{ }^{228} \mathrm{Ra},{ }^{224} \mathrm{Ra}\right.$ and $\left.{ }^{210} \mathrm{Po}\right)$ in Drinking Water. Applied Radiation and Isotopes, 65, 849-857. http://dx.doi.org/10.1016/j.apradiso.2007.01.022

[14] WHO (World Health Organization) (2011) Guidelines for Drinking-Water Quality. 4th Edition, ADDIN. 